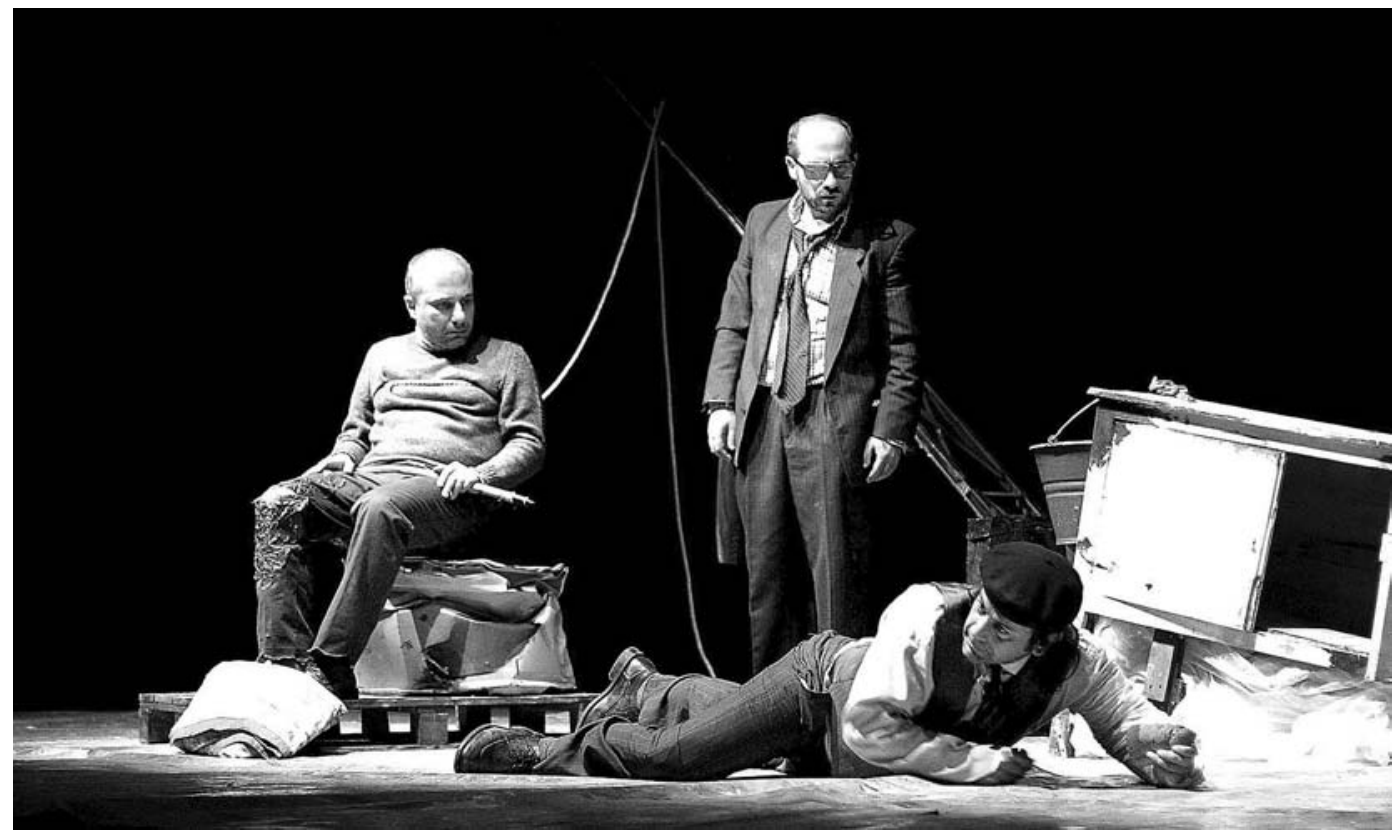

\title{
Poder dizer como se pensa
}

\section{Jorge Silva Melo}

Estávamos em Orléans, em princípios de Abril, no Teatro (Scène Nationale de Orléans), dirigido por Olivier Py e onde funciona, há anos, o Atelier Européen de Traduction, fundado pelo incansável Jacques Le Ny (www.ateliertraduction.com).

Éramos alguns, tradutores, autores, actores vindos de várias partes. Na tarde de sábado, 2 de Abril, o Jacques Le Ny pediu-me que apresentasse Antonio Tarantino, o autor de quem se iriam ler excertos das traduções francesas de Stabat Mater e Paixão segundo João. E eu, que nada preparara, que me preparara, sim, mas era para ouvir, pude dizer exactamente o que penso e como penso: "Adoro-o. É com certeza um dos mais importantes autores vivos e eu cá adorava representar a sua peça $A$ casa de Ramallah que já traduzimos e editámos em Portugal". E fiquei contente comigo e com o ambiente criado: é que pude dizer o que penso (e como penso) sem ter preparado, sem nenhumas dessas ferramentas com que actualmente se cerceia o discurso crítico, sem esse critiquês com que jornais, revistas, colóquios e universidades nos matam a paciência.

E se foi possível eu dizer o que penso (e como penso) - e ver o brilho nos olhos dos actores que iam ler, os meus amigos Evelyne Didi (actriz maior) e Olivier Cruveiller (cujo primeiro trabalho foi o meu filme Agosto, há vinte anos, para ai) - foi porque estes encontros que a Scène Nationale de Orléans organiza através do seu Atelier Européen de Traduction (a que pertencem várias estruturas europeias, entre as quais os Artistas Unidos) começaram a cimentar afectos, amizades, cumplicidades, descontracção, a verdadeira vida. E pude abraçar e beijar o velho senhor Antonio Tarantino, modesto, malandro, autor extremo de uma língua rara e de um mundo pobre ("devo tudo à segurança social, tenho vivido a minha vida com os apoios mínimos dos sem-abrigo, passo a vida a preencher papéis dessa burocracia, é um mundo que conheço bem, por isso posso falar dele", disse, com malícia e acrescentou sobre a sua mais recente peça, $A$ paz: "0 que não quer dizer que não queira tratar dos grandes assuntos do mundo, por isso nessa peça inventei um diálogo entre Sharon e Arafat sobre a coisa mais difícil que há na política, que é 'fazer a paz', demoram anos e anos em reuniões e nunca conseguem, quando eu acho que é a coisa mais simples, apertamos a mão e dizemos 'estão feitas as pazes' ou não é assim?").

Aos poucos, começou a constituir-se uma comunidade. Gente vinda da Grécia (a activissima Louisa Mitsakou), de Espanha (Alfonso Sylván, um dos eruditos mais apaixonantes com quem me cruzei, que, entusiasmado e modesto, tanto cita Píndaro como Karl Kraus como Max Frisch), de Itália (Tiziano Fratus sempre a perguntar por Letizia Russo, 0 bulímico Luca Scarlini que sabe tudo, conhece toda a gente, não dorme e é de extrema inteligência), de Bucareste, de França (François Berreur que, semanas antes, estivera em Lisboa connosco e voltaria depois, Bruno Tackels que há meses eu tentava contactar e com quem agora fiquei horas a falar na rua, à entrada de um sádico hotel "não fumadores" em que me meteram) e depois nós, o João Carneiro, a Alexandra Moreira da Silva, o José António Costa Ideias, o António Gonçalves.

Da literatura teatral portuguesa foi, este ano, lida uma peça de Jacinto Lucas Pires de quem o Atelier já apoiou versões francesas de Escrever, falare Coimbra b. E nesse mesmo dia, foram lidos excertos da obra de Dimitris Dimitriadis, o autor grego a quem o Atelier tem prestado mais atenção e de quem têm sido apoiadas traduções em francês, espanhol, italiano e português. Também houve uma conversa com o Autor, presente em todo o encontro, assim como o seu tradutor português, José António Costa Ideias. É um autor complexo, com uma atitude muito radical sobre a linguagem e a sua obra, considerável, ainda não terá recebido, fora da Grécia, a atenção que muito evidentemente merece (apesar de um dos seus primeiros textos ter sido objecto de uma encenação de Patrice Chéreau 


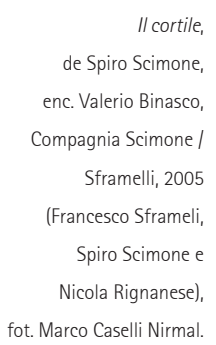

nos distantes anos 70). Uma edição portuguesa do teatro de Dimitriadis está em preparação (com o apoio do AET, claro). E será uma surpresa ouvir esta voz inquieta que nos interpela numa língua rica, original, sua.

E é para esses autores, originais, fora do circuito, com obra que não se atemoriza perante as regras e o mundo que o Atelier Européen trabalha - e para isso serve. E é por isso que eu posso dizer o que penso, tal qual, em jorgesilvamelês e sem universitalês, nestes encontros promovidos pelo AET. A pouco e pouco, uma real comunidade de leitores, de passadores, de amigos vai-se formando entre as senhas do almoço, as edições, as notícias dos ausentes ("O Juan Mayorga não vem porque vão encená-lo no Royal Court em Londres, está a rever a tradução que também foi apoiada pelo AET") e a marcação de encontros, entre o autocarro que nos leva ou o comboio suburbano, os espectáculos de que gostamos e não gostamos. Entre os textos que nos interessam e as descobertas que o não são.

Por isso pude dizer de Antonio Tarantino que o adoro. Que adoro a sua aposta num teatro verbal, torrencial, raivoso, inquieto, barroco, político, ambicioso, apóstrofe que vai fazendo ao mundo. E pude comover-me com Evelyne Didi quando ela me diz, depois de ter ouvido um excerto de Paixão segundo João "isto é uma peça para o André Wilms" (claro, o André Wilms, meu amigo e enorme actor, seria mais do que perfeito nesta raiva perante 0 mundo). É para estas ideias simples, descobrir um inédito, um texto que venha ao encontro das nossas noites, que este atelier serve: a palavra dos autores vai circulando, os actores encontram-se, o mundo passa.

Foi surpreendente o texto fantasmático de Eva Maliti, autora eslovaca, pela tendência alegórica e pela fantasia infantil: mais um texto sobre a vida depois do comunismo e a ausência do Pai-Grande Chefe. Mas a apresentação da autora foi, ainda, deslocada neste ambiente que ganha descontracção: era difícil ouvir o que a apresentadora ia lendo num texto universitário talvez complexo mas aqui deslocado na sua frieza, fora de sítio nesta informalidade que se foi adquirindo, nestes afectos que se vão criando.

Inesquecivel foi a manhã passada no estúdio do coreógrafo Josef Nadj com o grande crítico italiano Franco Quadri, editor do Ubulibri e agitador cultural desde os longinquos anos 60. Durante mais de três horas, e perante um grupo restrito de entrevistadores, Quadri foi contando a sua vida, a mudança dos seus gostos, as suas apostas, as aventuras que foi vivendo. Com o Living Theatre, com Peter Stein, com Luca Ronconi e o Orlando furioso, com Tadeusz Kantor, com a crítica, com Klaus Michael Grüber, nesse permanente acompanhamento crítico e militante, em que viu a queda de todos os dogmas. E nós íamos revivendo as nossas vidas também ao lado de um
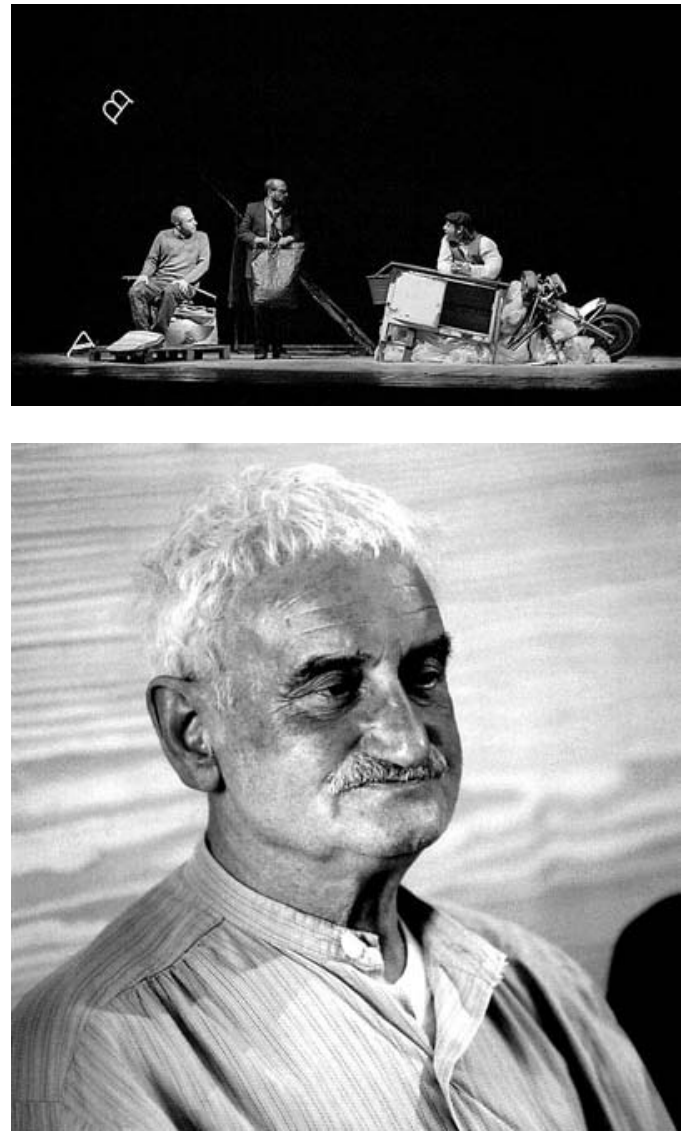

pensamento que nos foi vivendo. Essa longa entrevista será montada e traduzida e foi um encontro irrepetivel. Também porque Quadri pôde "dizer o que pensa", e "como o pensa", em voz baixa, hesitante, com esquecimentos, com busca de palavras, com humanidade.

È essa humanidade que pede o espectáculo // cortile de Spiro Scimone apresentado na Sala Grande no sábado à noite. É a quarta peça de Scimone depois dos grandes êxitos que teve com Nunzio e A festa (cujas traduções para português foram também apoiadas pelo AET).

Haverá quem lamente que Scimone tenha abandonado a comédia metafísica mas regional de algum dos seus textos iniciais e se tenha lançado para um mundo metafórico que inevitavelmente lembra o Beckett de Fin de partie com as suas figuras no crepúsculo da humanidade, as suas acções surreais, o seu imobilismo existencial. Eu considero a peça de uma coragem fantástica: não é dificil escrever depois de lonesco, muitos são os que escrevem depois de Albee, muitos são os que agora ouvem Harold Pinter, mas é como se Beckett tivesse paralisado o teatro e a sua escrita, amaldiçoado o palco com o seu silêncio. Scimone (e os seus extraordinários actores Francesco Sframeli e Nicola Abignanese) ousam-no. Não temem suceder a Beckett, usam-no.

E eu, com eles, vejo mais deste mundo e deste capitalismo.

0 espectáculo esteve dias depois em Lisboa, no Teatro Taborda. Quando nos despedimos, no autocarro que nos depunha em Paris, junto ao Théâtre de La Ville, Place du Chatelêt, domingo de sol primaveril, dissemos "até já".

Porque vamos sendo um grupo, uns amigos, pessoas, gente que gosta de pensar o que diz e vai dizendo o que pensa, como quer e como pode. 